\title{
"Reinventing the wheel over and over again". Organizational learning, memory and forgetting in doing diversity work
}

Organizational learning, memory and forgetting

Marieke van den Brink

Gender and Diversity Studies, Radboud University Nijmegen, The Netherlands

\begin{abstract}
Purpose - One of the urgent questions in the field of diversity is the knowledge about effective diversity practices. This paper aims to advance our knowledge on organizational change toward diversity by combining concepts from diversity studies and organizational learning.

Design/methodology/approach - By employing a social practice approach to organizational learning, the author will be able to go beyond individual learning experiences of diversity practices but see how members negotiate the diversity knowledge and how they integrate their new knowledge in their day-to-day organizational norms and practices. The analysis draws on data collected during a longitudinal case study in a financial service organization in the Netherlands.

Findings - This study showed how collective learning practices took place but were insufficiently anchored in a collective memory. Change agents have the task to build "new" memory on diversity policies and gender inequality as well as to use organizational memory to enable diversity policies and practices to be implemented. The inability to create a community of practice impeded the change agenda.

Research limitations/implications - Future research could expand our knowledge on collective memory of knowledge on diversity further and focus on the way employees make use of this memory while doing diversity.

Practical implications - The current literature often tends to analyze the effectiveness of diversity practices as linear processes, which is insufficient to capture the complexity of a change process characterized with layers of negotiated and politicized forms of access to resources. The author would argue for more future work on nonlinear and process-based perspectives on organizational change.

Originality/value - The contribution is to the literature on diversity practices by showing how the lack of collective memory to "store" individual learning in the organization has proven to be a major problem in the management of diversity.
\end{abstract}

Keywords Diversity practices, Organizational learning, Organizational memory

Paper type Research paper

\section{Introduction}

Despite numerous initiatives aiming to transform organizations into more equal, inclusive and diverse work places, progress remains - at best - slow (Dobbin and Kalev, 2016; Evans, 2014). Diversity practices rarely translate into deep systemic change (Acker, 2006; Leenders et al., 2019), as interventions often stay superficial (Ahmed, 2007; Eriksson-Zetterquist and Styhre, 2008), geared toward fixing women/minorities (Ely and Meyerson, 2000; Zanoni et al., 2010) and are implemented rather ad hoc (Benschop et al., 2015; van den Brink, 2018) or even become counterproductive (Romani et al., 2019). In addition, planned diversity interventions

(C) Marieke van den Brink. Published by Emerald Publishing Limited. This article is published under the Creative Commons Attribution (CC BY 4.0) licence. Anyone may reproduce, distribute, translate and create derivative works of this article (for both commercial \& non-commercial purposes), subject to full attribution to the original publication and authors. The full terms of this licence may be seen at http:// creativecommons.org/licences/by/4.0/legalcode.

Funding: Nederlandse Organisatie voor Wetenschappelijk Onderzoek. 451-11-024.

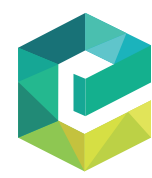

Equality, Diversity and Inclusion An International Journal Vol. 39 No. 4,2020 pp. $379-393$ 
EDI 39,4

\section{0}

barely lead to sustainable change in the long run as it is difficult to change norms and daily practices of organizational members (Eriksson-Zetterquist and Renemark, 2016; Acker, 2000).

This paper contributes to the literature on organizational change toward equality, diversity and inclusion by exploring how diversity interventions can be (better) institutionalized in organizations. To do so, this paper applies a learning perspective (Gherardi, 2006) to the implementation of diversity interventions. Although many diversity scholars emphasize the role of learning in diversity management (o.a. Dass and Parker 1999; Ely and Meyerson, 2000; Moss-Racussin et al., 2014), only few of them engaged with the rich literature on organizational learning. These studies mostly focus on individual learning; for instance Welp (2002), Van den Brink (2015) and Lansu (2019) analyze the (non)learning process of white male managers. Other studies focus on the individual learning effects of particular interventions such as diversity training (Alhejji et al., 2016; Fujimoto and Härtel, 2017). In this paper, the focus lies on organizational learning: the way knowledge becomes embedded in day-to-day organizational practices and routines (Gherardi, 2006). Using the concept of organizational learning will help to go beyond the cognitive learning process of individuals and explore how individual learning can lead to learning on an organizational level. Learning theories address how learning processes can be institutionalized, meaning how structures, processes and strategies that facilitate learning at the organizational level can be established and maintained (Romme and Van Witteloostuijn, 1999). The main research question therefore is: how do organizational members institutionalize their individual learning process to change in organizational cultures, routines and structures in a sustainable way? I substantiate my argument with a longitudinal case study in a financial service organization in the Netherlands.

\section{Diversity initiatives}

In different geographical and organizational contexts, scholars have been theorizing about effective diversity initiatives (Dobbin and Kalev, 2016; Evans, 2014; Klarsfeld et al., 2019). Diversity initiatives are a set of formalized practices developed and implemented by organizations to manage equality, diversity and inclusion. Scholars argue that most effective diversity initiatives are the ones aimed at "diminishing inequality regimes by changing everyday organizational work practices, routines and interactions so that they stop (re) producing institutionalized inequalities" (see Acker, 2006). Yet, studies on these transformational interventions are rare and leave us with little indication of how to start transforming norms and practices in a sustainable way (De Vries and Van den Brink, 2016; Benschop and Verloo 2011). This paper extends our knowledge on how organizational members can most effectively facilitate the kind of organizational change that transforms organizations. To do so, this paper builds on literature on the roles change agents can have in challenging systems and structures to improve equality, diversity and inclusion and connects it with literature on organizational learning.

To gain a better understanding of how to change organizations more effectively, diversity scholars have focused on the role of change agents in organizations. Actor-focused perspectives are important in understanding the unfolding of institutional change processes (Battilana et al., 2009). Rather than seeing organizational change as orchestrated from the top, I agree with Orlikowski (1996), who sees it as "grounded in the ongoing practices of organizational actors, and [emerging] out of their (tacit and not so tacit) accommodations to and experiments with the everyday ...”. These studies give us valuable insights on the motives (Cockburn 1991; Kirton et al., 2007), actions (Tatli and Ozbilgin, 2009; Meyerson and Scully 1995; Parsons and Priola, 2013; Lawrence 2000) and the individual learning processes (Welp 2002; Van den Brink 2015; Lansu 2019) of change agents. Change agents require 
knowledge on differences, power and inequality, which in turn is foundational to challenging inequality regimes in organizations, through their capacity to change work practices (De Vries and Van den Brink, 2016; Lansu et al., 2019). However, the current literature lacks insights on how, for instance, individual awareness can be institutionalized in the organization in a more sustainable way. To contribute to the literature on diversity practices and gain more insight into change processes toward equality, I therefore turn to concepts from organizational learning theory.

A learning perspective can help give a better understanding of why certain initiatives on transformational change are successful or not, to explore areas for improvement and to improve the linking of individual to organizational learning, leading to sustainable change. Insights from learning theory may be a fruitful way to gain insight into the way norms and practices are reinterpreted, renegotiated and institutionalized. Yet, scholars who have connected organizational learning with diversity are scarce. Foldy and Creed (1999) studied the change process toward more GLBT inclusivity in a US-based financial firm. They argue that collective deeper learning cannot happen until first individuals learn to question their own value system: "To foster company-wide change, one must highlight individual work" (p. 224). Lorbeiki (2001) warns that a learning perspective on diversity management could lead to "political naiveté" as it emphasizes the need to introduce diversity into core work processes and into the strategic areas of the organization, which is likely to be by those in power positions. I will build on these studies by connecting individual to organizational learning.

\section{Organizational learning and learning practices}

Most organizations are under pressure to evolve and adapt to changes in the surrounding marketplace, society and natural environment (Crossan et al., 1999). Organizational learning is the process by which an organization asserts these changes with questions of current practice and attempts to evolve the culture, structure and processes that are most central to the organization (Schwandt, 1997). Some researchers study organizational learning by measuring cognitions of organizational members, while other researchers shifted their focus on the collective practices of people within organizations and how organizations learn as systems of shared meanings (Nicolini et al., 2003; Schwandt, 1997). For instance, Yanow (2000) proposed a cultural perspective on learning to theorize about the collective aspects of organizational learning. Using the concept of culture, she argues, allows us to explore what learning by a collective - organizational learning - might look like. A cultural perspective on learning focuses on what "we can see when we look at what people do, rather than searching for what might be going on only their heads" (Yanow, 2000, p. 253). In this tradition, learning is a social activity rather than merely a cognitive activity (Gherardi, 2006) and in which knowing is not separated from doing. Learning is seen as "an integral and inseparable aspect of social practice" (Lave and Wenger, 1991, p. 31). Situated learning perspectives understand processes of knowledge formation and sharing as integral to everyday work practices (Contu and Willmott, 2003). Through the process of sharing information and experiences in a community of practice, group members can learn from each other and have an opportunity to develop personally and professionally (Lave and Wenger, 1991). Therefore, I define organizational learning in line with Gherardi (2006) as the way knowledge becomes embedded in day-to-day organizational practices and routines.

Practices of organizational learning can be seen as the development of an organization's memory (Cross and Baird 2000). An organizational memory is an aspect of an organization's history in which knowledge and behavior are captured and stored in such a way that they become accessible in the future. One of the major contributions in this field is by Walsh and Ungson (1991), who argued that memory is "contained" within multiple "storage bins", vehicles or "carriers". These storage bins or memory carriers overlap and are interrelated 
EDI 39,4

382

(Van der Bent et al., 1999; Fiedler and Welpe, 2010). New knowledge can be embedded in a variety of repositories or knowledge reservoirs, including tools, routines, social networks and transactive memory systems (Walsh and Ungson, 1991).

When talking about what is learnt and part of a collective memory, we should not omit the other side of this concept, which is the knowledge that is not incorporated in a collective memory, that is, forgetting. As Casey and Olivera (2011) show, "memory and forgetting are inextricably linked processes of knowledge enacted, created, retained and decaying" (p. 306). Forgetting happens when organizations either fail in the structural acquisition of knowledge, that is, when new knowledge is not included in the organization's memory, or when they fail to retain certain knowledge. In the mainstream literature on organizational learning, there is a "focus on formal channels and strategies for transmitting and pooling knowledge, often within specialized context such as the classroom, training sessions or mentoring" (Contu and Willmott, 2003, p. 292). This also is the case for studies on diversity training that mainly focus on the individual cognitive and behavioral learning of participants (Alhejji et al., 2016; Fujimoto and Härtel, 2017). By employing a social practice approach to organizational learning, I will be able to go beyond individual learning experiences but see how members negotiate the diversity knowledge and how they integrate their new knowledge in their day-to-day organizational practices.

\section{Case and methods \\ Research strategy}

As complex change and learning processes can only be captured by research over a longer period of time with multiple methods (Pettigrew, 1990), the research strategy in this paper is a longitudinal case study approach. The empirical research took place over a period of two years from February 2014 to May 2016. We selected a unique case (Eisenhardt and Graebner, 2007): a large financial service organization with a long history of gender and diversity policies, which actively aimed to institutionalize diversity practices. The organization is situated in a large city in the western part of the Netherlands, employing 20,000 people. To demarcate the research and enable an in-depth study, I specifically studied the Human Resources (HR) department and the Diversity and Inclusion (D\&I) department. These departments drew up an integrative diversity plan, focusing on the development of diversity expertise and awareness of the recruiters and the diversification of the recruiter pool, but also on renewal of the labor market communications. The policy plan mainly focused on gender and ethnicity. In this paper, I focus on the learning of the recruiters over a longer period of time and embed this in the overall diversity initiatives of the HR and D\&I departments.

\section{Data collection}

Practice-based studies rely heavily on ethnomethodology, in which the most suitable methods for examining practices are participant observation and accompanying in-depth interviews; that is, actually seeing what people say and do (Yanow, 2000). Data were collected in three ways. First, I conducted tape-recorded interviews with 30 individuals in different positions who were involved in the integration of diversity in the HR department, such as the D\&I officer, HR manager(s), recruiters and line managers. Some of these interviews were informal and occurred when people were working, on their lunch break or during diversity events and network meetings. They provided information about their perceptions of diversity policies and learning experiences. At least 20 interviews were planned and included the recruiters and line managers. In these open, in-depth interviews, respondents were asked to describe their learning process and experiences with implementing their knowledge in their day-to-day work. Topics included: diversity (what does it mean to you), experiences with 
diversity training (what have you learned from the training) and how do you apply this knowledge in your current work practices (anchoring), especially in recruitment and selection (how do you implement the diversity knowledge in your work). In an attempt to capture the learning process in as much detail as possible, I encouraged the interviewees to talk about specific critical incidents and learning experiences, rather than limiting their discussions to generalities.

The second method of data collection involved nonparticipant observations. I gained access to over 20 meetings between the HR and D\&I or within HR about how to integrate diversity in their practices. In addition, I observed interactions in multiple diversity training sessions for different target groups. These observations provided more than $40 \mathrm{~h}$ of observations, which enhanced my knowledge on how the topic of diversity was discussed in the company and the difficulties that arose when HR and diversity managers attempted to institutionalize diversity in the organization. Due to privacy issues, I was not allowed to be present during recruitment and selection procedures.

The third method of data collection involved documents that provided insight into official diversity policies and planned activities. Most of these documents were strategy documents (D\&I strategy plans, year plans of HR department) and diversity communication documents, such as the new recruitment campaign, a diversity magazine and the website. These documents provided information about the objectives of the diversity initiatives and the diversity discourse within the company. It also included a survey about the (learning) experiences following the training session in 2014.

\section{Data analysis}

An abductive approach (Van Maanen et al., 2007) was used, which implies an iterative process of going back and forth between the academic literature on organizational learning and memory and the empirical material. I used the qualitative software package ATLAS-ti to systemize and code our empirical material. As the basis for my initial analyses, I reread my field notes, reviewed all written documents and transcribed the interviews.

The first coding was done by breaking the text into relatively small units of content. Interview topics served as a first guide for this coding process (Silverman, 2006). The text was scanned for essential words and phrases connected to topics as the diversity interventions, awareness, integration in structure or culture. This coding process provided a large number of codes that stemmed from the topic list, the data or both. This first phase showed that learning on the individual and collective level was an essential part of the effectiveness of diversity practices. Going back to the literature on change and learning, I started to link theoretical learning concepts to empirical material. The data were used to answer the following questions: What kind of learning practices could be identified? Where and when did these learning practices take place on an individual and organizational level, and where not (forgetting)? What facilitated or hindered embedding individual knowledge to the organizational level in new norms and practices (organizational memory)?

\section{Findings}

Further I discuss the findings by using concepts taken from learning literature - individual and collective learning, organizational memory and forgetting. I will start with information about the implemented interventions.

\section{The interventions}

All recruiters and line managers were invited to a compulsory diversity training that focused on the impact of diversity on evaluations during recruitment and selection, performed by two external diversity consultants. The training sessions for the recruiters lasted one full day and 
EDI 39,4

\section{4}

included practicing with actors. The training sessions for the top 100 line managers were half a day and only included a lecture and some brief exercises. The main goal of the day was to discuss the "mould" the company used in terms of criteria to hire trainees. These criteria were considered to be too narrow, with the consequence that especially white heterosexual men with an educational background in finance, economics or law from the Randstad (western urban part of the Netherlands) were successful in the application process. The underlying idea was that recruiters lacked the knowledge and skills to assess the qualities of women and ethnic minority applicants and that implicit bias led to the undervaluing of these groups. These training sessions were succeeded by multiple initiatives focusing on the diversification of the recruiters, thematic events to develop diversity expertise and awareness of the recruiters and a renewal of the labor market communications.

\section{Individual learning practices}

There was evidence of learning on an individual level. Managers and recruiters were stimulated to question how they operationalize and apply selection criteria when assessing candidates. During the training sessions, recruiters and managers were encouraged to talk about the current criteria such as "ambition", "showing initiative", "backbone", "decisiveness", "fierceness", "representative" and how they recognize these qualities in candidates.

An important bias that came to light during the first training session for recruiters was the concept of ambition. When it comes to trainees, recruiters are primarily looking for people who are very clear about what they want and are very direct: 'So, these are my ambitions. I am X and I want to be there in 5 years' time. And this is what I have to offer, tell me what you can offer me.' And it was found that a quality was linked to this directness and that this was somehow different for biculturals, and also for women. (John, recruiter, ethnic majority, 2014)

Recruiters such as John learned that their Western bias may prevent them from seeing the qualities in people who are not similar to them or the "typical successful candidate", that is, their image of the "ideal worker" (Tienari et al., 2002; Acker, 2006). The training session highlighted a bias for, for example, women with children, students who had belonged to a Christian study club, candidates with an unkempt appearance and ethnic minorities (observation training sessions, 2014). Learning occurred as the participants were challenged to renegotiate and reinterpret the way new recruits are evaluated. For example, a group of recruiters discussed whether showing "ambition" or "initiative" is also possible with a candidate who has been working in the family business instead of their standard way of assessing these qualities by asking whether candidates were board members of a student association (observations during training sessions, 2014). The interviews and evaluation survey show that respondents gained new insights such as how women and people from a different cultural background may react differently to interview questions ("I am much more aware of the differences and the importance of looking at people with an open mind"). Furthermore, the employees became more aware of their own actions and unconscious thoughts ("I discovered that I have a preference for this specific type of trainee", "But I still looked for what I'm familiar with". (survey 2014).

The goal of the training seems to be met as the respondents who participated in it say that they are more aware of their stereotypes and perceptions. However, it should be noted that this does not necessarily mean that the participants are actually able to transfer their assumptions into changed behavior in the way they recruit and select new employees in their daily practices. In the evaluation survey several participants indicated that the training sessions should be repeated to "anchor it in our daily practices" and that "the continuity of the training, should be safeguarded". Recruiter Anna argues "we become conscious of our own perceptions and observations, but we should train that regularly." Studies have shown that 
the learning in awareness training is highly dependent on repetition. A sequence of integrated training programs is therefore deemed more effective compared to other programs, in particular the stand-alone training with a "check-the-box" approach (Bezrukova et al., 2012; Benschop et al., 2015). This leads us to organizational learning.

\section{Organizational learning}

There were some signs that the individual learning practices lead to collective learning on an organizational level. Organizational learning necessarily involves individuals' transformative learning through a process of critical reflection (Henderson, 2002) on norms and work practices that create inequality and privilege. It is an ongoing learning process away from the status quo, involving individuals who continuously identify and revise organizational norms and work practices and ultimately become more reflective about their assumptions, attitudes and behavior. After the training, some recruiters started to question the current recruitment method including the procedure and criteria used to select new employees. They questioned the cultural insensitivity of the IQ test used, as many ethnic minority candidates fail this test and subsequently are not invited for interview. In terms of the criteria: instead of only learning how to avoid bias when applying the current criteria, they discussed whether the current criteria are actually causing inequality and whether the organization forces "others" to adjust to the dominant norms and values when hired.

We have a very narrow mould. What use is diversity if we are all the products of the same upbringing? (Tanja, recruiter, ethnic majority, 2015)

Perhaps we should be looking for a completely new set of criteria that have much more to do with who we want to be as an organization. And this is where we want to make an impact, our image is corporal, Amsterdam, arrogant, the best. And perhaps we should be aiming at a completely different type of bank and different people. (Eric, manager, ethnic majority, 2014)

Tanja reflects on the "narrow mould" used to recruit new employees and on the risk of assimilation. The strong culture of the organization may result in "others" leaving the organization after a while because they do not feel comfortable, or they do not become assimilated in the dominant culture. Only the latter would not create a culture of diversity in her opinion. Eric proposes to align the selection criteria with the new strategy and espoused image of the organization after the financial crisis. Eric believes that the current criteria would attract the same people who had caused problems in the past. Recruiting people who do not exemplify the corporal, arrogant, cocky and hypermasculine image of the bank may help to transform the culture and external image of the bank. Eric wants to relate diversity to the organization's strategy and core activities so that "the work becomes diversified, not just the staff". The same discussion was held during the meetings of the Diversity Board, a board that is made up of a member of the executive board and directors of the divisions.

One of the directors, Vincent, argued during a diversity meeting that diversity should be lined to the identity and culture of a bank. "The past has shown that homogeneity doesn't give - how can I put it the best results. In my opinion we need diversity to become the kind of bank we want to be". (Observations, diversity board, 2014)

Although Vincent, Eric and Tanja explicitly make the link between diversity and the fundamental design, goals and activities of the organization, these insights remain very abstract and to a large extent rhetorical. In other words, there is barely any discussion of criteria that would be more suitable for the new identity the bank wants and of how to communicate, discuss and implement these criteria. One executive recruiter questions the current norms and finds a way to do this in a more concrete manner. 
EDI

39,4

For this new team it came down to the choice between two candidates: both women and both good. One of them was a typical bank girl, nice and safe. Attractive, pleasant. And the other candidate was different. In appearance, but also in how she acted. Non-conformist. And they were tending towards the nice safe one. . . and then I said: but you want to be innovative, you want the bank to do things differently do not you? Shouldn't this be reflected in your team too? That it's different and that you do things differently? And they changed their mind immediately - so it was a very appropriate intervention in my opinion. We must dare to be open to real diversity and dare to make unconventional choices. (Carly, executive recruiter, ethnic majority, 2016)

Carly intervened in a procedure and tried to challenge in concrete terms the mental map of her colleagues. She managed to make diversity part of the daily practices and policy. It led to questions such as "What is competence?" and to the observation that the choice between the two candidates was not an ethnicity-neutral (or gender-neutral) decision. Although it was very hard for recruiters to reassess their current criteria, some discussions developed around which norms or criteria recruiters were willing to relax to make it more welcoming for "others" (observation report 2015).

\section{Conditions for organizational learning practices}

First, the training sessions and all the attention for diversity in the HR department created the conditions for a learning community to develop the ability to deal with difficult and emotionally charged topics. Second, the interventions were coupled to organizational targets that are in line with the company culture.

A factor that promoted collective learning was that in 2014 diversity was integrated into the whole HR department, both in the general policy, recruitment and selection and in internal and external communication. This opened up a space in which the topic of diversity in HR was available for discussion and interpretation, a community of practice (Lave and Wenger, 1991). A small number of recruiters agreed to give one another feedback after the training and to continue to reflect on their experiences with diversity in the daily practice of recruitment and selection. In the selection interviews they sat next to one another to learn from one another and to give one another feedback on possible advantages and stereotyping. In all internal and external communication, there was better representation of a diverse group of people, special trainee information days were organized for a wide range of talent and there was a "diversity tree" internally in the department, where new ideas on diversity could be pitched.

During the months after the training, diversity becomes a focal point of the department. It is visually present by a "diversity tree", a tree positioned central in the work space where recruiters can place memo's with ideas, dilemma's and suggestions. I regularly see people standing around the tree and discuss new input, and also during lunches ideas are shared. (Observation notes, 2015)

External communication was also tackled as the result of discussions with recruiters after the training. To achieve less emphasis on the narrow "mould" of requirements that the bank sets with regard to potential employees, the HR department invited potential employees to come and tell their own unique story.

Second, organizational learning practices were stimulated by linking specific target figures for recruiting woman and ethnic minorities to the various business units. In the years 2014-2016, the results of the various business units were assessed by means of key performance indicators (KPIs) in the Diversity Board, a meeting at which the directors of all divisions were present under the leadership of a member of the Executive Board. By making diversity a performance indicator, it was included in progress reviews with line managers, and it was more difficult for the theme to disappear off the agenda. It also had an effect on the organizational culture of competition between the business units. "No-one wants to be last. They actually give me a call: 'Yvonne, I've taken on another woman”' (Yvonne, D\&I officer, 
ethnic majority, 2015). The target figures adhered to the dominant culture of the organization, which is characterized by audits, performance indicators and the language of statistics. Ahmed and Swan (2006) warn, however, that the emphasis on diversity as a performance indicator can result in a superficial approach to "showcasing success". Or as Prasad and Mills (1997) already concluded a long time ago that the technologies of "showcasing" can lead to an economy of affect in which pride, celebration and upbeat performances hide the frustrations, anger, tensions and disappointment of living with the effect of diversity work.

\section{Lack of organizational memory: forgetting}

Although individual and organizational learning practices occurred, it was hard to anchor these in the collective memory of the organization. We could refer to this process as "forgetting". Forgetting happens when organizations either fail in their acquisition of knowledge, that is, when new knowledge is not included in the organization's memory, or when they fail to retain certain knowledge, that is, when knowledge that was part of the organization's memory is lost (Casey and Olivera, 2011). Forgetting at the organizational level was mainly caused by the high internal staff mobility in the organization. The majority of recruiters, who followed the training and had been strongly engaged in issues of diversity in recruitment and selection during 2014, moved to other jobs inside (and outside) the organization during 2014-2015. Although they had the opportunity to practice their knowledge and skills in their new positions, the newly attracted recruiters missed the learning experiences of their predecessors as the training was not repeated after 2014. The follow-up training sessions were for a large group of trainees their first session, resulting in a training session that had to go back to the basics (observations training sessions 2015) and could not build on earlier learnings of a community of practice (Lave and Wenger, 1991). The high mobility of staff makes a sequence of training sessions that build on each other almost impossible.

The high mobility of staff in the organization was also illustrated by the transfer of Susan, the head of HR, who had been the driving force of the diversity strategy. After she left at the end of 2014, an interim manager took over for seven months before Mary was appointed as new head. There had been a knowledge transfer between Susan and the interim manager, and the interim manager and Mary, but diversity was not a topic during the meeting between the interim manager and Mary. Mary clearly assigned less priority to issues of diversity from the start. In the HR policy of 2016, diversity was no longer a focus point and there was no reference to diversity in the document at all. Mary explains:

This year diversity is no longer mentioned as a specific theme in my annual plan. It's almost business as usual. It's up to the recruiter that he [sic] pays attention to it, like hey: how's it going with your target? And if it's a woman, then you choose a woman. So it's no longer an explicit theme. But this isn't because it's no longer in our heads, but because it's a kind of underlying something that's there all the time. (Mary, HR manager, ethnic majority)

Although the new HR manager is convinced that the diversity theme is anchored in the daily $\mathrm{HR}$ practices, other respondents say this is not the case. "I'm worried about the way that the theme gets forgotten [within HR]. We have to bear it in mind all the time" (Yvonne, D\&I officer). The HR employee who has diversity in her portfolio is also critical of the lack of attention for diversity: "It is now less normal, I have to start from the beginning each time, as there is really less attention paid to the theme" (Hemalatha, recruiter, ethnic minority, 2016).

Because of the fast turnover of the champions of diversity, it is difficult to make diversity a long-term theme within organizations, which means that it is also not sufficiently anchored in the organizational norms and practices. This is in line with research that shows that the departure of people raises concerns regarding the loss of expertise and organizational memory (Casey, 1997). A diversity function is generally a temporary career step, so that the 
EDI 39,4

\section{8}

turnover in this position in the organization is high (Smith and Parker, 2005). Unfortunately, when someone leaves, this person takes the knowledge (s)he has obtained and the network (s)he has built up, and often his/her successor has to start right from the beginning again. There is also no collective memory on the diversity theme in the HR department. Because Susan moved on and due to the limited interest of Mary for the diversity subject, knowledge on diversity and successful initiatives was not sufficiently embedded in the collective memory of the organization.

The fast turnover of and the poor handover between diversity professionals in organizations does not just mean that the new diversity manager has to start over again, it also has consequences for the anchoring of the policy in the organization. Since the 1980s of the last century, the organization has been concerned with the area of emancipation, gender equality and diversity. However, there is little information available from these years for the current D\&I department. The D\&I head was appointed in 2012 when - after the economic crisis - diversity became a strategic issue once more. Before the economic crisis, the organization was much advanced in the area of D\&I, but this knowledge from this period is not available to the current D\&I manager. "When I started here there was nothing about previous diversity managers. No policy, no documentation, no handover. The HR manager is also new, so this person could not hand over to me either. I have the feeling we reinvent the wheel over and over again." (observation from talk with D\&I officer).

\section{Discussion}

The aim of this paper is to advance our knowledge on organizational change toward equality, diversity and inclusion by exploring how diversity interventions can be (better) institutionalized in organizations. By applying a learning perspective (Gherardi, 2006) to diversity initiatives, we gained a better understanding of how individual knowledge becomes embedded in organizational practices and norms (or not) (Gherardi, 2009; Nicolini et al., 2003). This study contributes to the growing body of research examining the possibilities and difficulties of diversity initiatives to create more equitable organizations (Dobbin and Kalev, 2016; Ortlieb and Sieben, 2012; De Vries and Van den Brink, 2016). The main research question therefore was: how do organizational members institutionalize their individual learning process to change in organizational cultures, routines and structures in a sustainable way? Further, I present the theoretical lessons learned from the analysis of the data.

The individual learning of organization members led in some instances to organizational learning practices when recruiters collectively renegotiated and reinterpreted the way new recruits are evaluated. They discussed unequal procedures, norms and practices in their organization and in their daily practices. Important conditions for these learning practices were the integration of diversity in the whole HR department, both in the policy and in the internal and external communication, and the setting of target figures for the recruitment of women and ethnic minorities in the different business unit. This made the topic of diversity in recruitment and selection available for discussion and interpretation. Problems that previously could not be discussed became open for discussion, which led to shared interpretations, a common language, shared frameworks, symbols and stories (Rowlinson et al., 2014). This can be understood as a learning community. Organizational learning requires actors to engage in ongoing dialogues, "in which defensive reasoning and behaviour do not impede free and open inquiry" (Romme and Van Witteloostuijn, 1999, p. 440). In addition, learning was stimulated by linking specific target figures for recruiting woman and ethnic minorities to the various business units. This adhered to the dominant culture of the organization, characterized by audits, performance indicators and the language of statistics.

However, the inability to sustain a learning community impeded the building of an organizational memory. Especially the high internal staff mobility in the organization and poor knowledge transfer between successive diversity officers resulted in a lack of collective 
memory on diversity. Diversity officers and employees succeeded one another quickly, and knowledge on effective practice and the reproduction of inequalities in the organization was easily lost. This is problematic as "without a structure which (to some extent) institutionalizes and facilitates learning, this momentum easily breaks down" (Georges et al., 1999). Knowledge and experiences were lost and diversity as a strategic HR topic disappeared from the agenda, as it was not firmly anchored in the daily organizational routines and practices. Change agents such as diversity officers and HR managers were not able to build a "new" collective memory on diversity policies and did not use organizational memory (e.g. an organization's mission, previous diversity policies) to help implement diversity policies and practices. This is in line with research that shows that the departure of people raises concerns regarding the loss of expertise and organizational memory (Casey, 1997). When individuals are removed from their group context, the knowledge and skills they had as part of the group are ineffective or even seem to disappear (Lave and Wenger, 1991).

\section{Implications for further research and practice}

The difficulty to create sustainable change in diversity work is a problem that many organizations face. The mobility of diversity officers cannot easily be countered, but the organization might consider this position as a "real" career where people need skills and expertise to function well. Often, these positions are poorly paid, with limited career possibilities, or seen as temporarily (see also Lawrence 2000). Also, to create a broad responsibility in the organization, the issue of diversity should not only be a topic of HR, but diversity management must be the responsibility of managers at all levels in the organization (Forster and Harris 2005) under monitoring of a diversity committee (see also Dobin and Kalev, 2016). Secondly, the lack of storage of knowledge made that new diversity managers reinvented the wheel again. Although the organization had a long history of gender and diversity initiatives, nothing was stored in internal documents, hampering individual and organizational learning. Good communication and storage of information are important for continued organizational learning and building a collective memory (Fiedler and Welpe, 2010; Smith and Parker, 2005).

For future research on change toward more diversity and inclusion, I would argue for more longitudinal research to capture the dynamics of learning and change. This means questioning our own theoretical understandings of organizational change in relation to equality and diversity, how it occur and how we might observe it (Cavaghan 2013; Meier 2006). There is often an underlying presumption that change is a linear progression. This research shows that progress is vulnerable and internal and external pressures, for instance, the financial crisis or mergers, can throw progression back. Although a process-based view on change is common in the field of (critical) diversity management (Janssens and Steyaert, 2019), we often hold a linear view in terms of outcomes (van den Brink, 2018). This study showed that organizational learning is a continuous and iterative process in which an environment is created in which organization members can learn, reflect and experiment. Organizational learning requires interventions that involve a continuous discussion and revision on the norms that underlie work practices in organizations. Therefore, I argue to use more nonlinear process-based perspectives on organizational learning (Davies and Thomas 2008; Hernes 2008) toward diversity in future studies. The process-based perspective within organizational theory implies focusing on "changing" as a process (Weick and Quinn 1999), rather than analyzing change as a linear, rational and logical process. In this way, we can analyze the complexity and polyvocality of learning and change processes and contexts (Davies and Thomas, 2008) and allow focusing on processes of power and the politics of doing diversity. These studies provide a more complex view on the intertwinement of diversity initiatives with a myriad of inequality practices that cover up, intertwine or even hijack diversity initiatives. 
EDI

39,4

390

\section{References}

Eriksson-Zetterquist, U. and Renemark, D. (2016), “Can changes to gender equality Be sustained?”, Gender, Work and Organization, Vol. 23 No. 4, pp. 363-378.

Acker, J. (2000), "Gendered contradictions in organizational equity projects", Organization, Vol. 7 No. 4 , pp. $625-632$.

Acker, J. (2006), "Inequality regimes: gender, class, and race in organizations", Gender \& Society, Vol. 20 No. 4, p. 441.

Ahmed, S. (2007), "You end up doing the document rather than doing the doing': diversity, race equality and the politics of documentation", Ethnic and Racial Studies, Vol. 30 No. 4, pp. 590-609.

Ahmed, S. and Swan, E. (2006), "Doing diversity work", Policy Futures in Education, Vol. 4 No. 2, pp. 96-100.

Alhejji, H., Garavan, T., Carbery, R., O'Brien, F. and McGuire, D. (2016), "Diversity training programme outcomes: a systematic review", Human Resource Development Quarterly, Vol. 27 No. 1, pp. 95-149.

Battilana, J., Leca, B. and Boxenbaum, E. (2009), "2 how actors change institutions: towards a theory of institutional entrepreneurship", Academy of Management Annals, Vol. 3 No. 1, pp. 65-107.

Benschop, Y. and Verloo, M. (2011), "Gender change, organizational change, and gender equality strategies", in Knights, D.Jeanes, E. and Yancey-Martin, P. (Eds), The Sage Handbook of Gender, Work and Organization, Sage, London.

Benschop, Y., Holgersson, C., Van den Brink, M. and Wahl, A. (2015), "Future challenges for practices of diversity management in organizations", in Bendl, R., Henttonen, E., Bleijenbergh, I.L. and Mills, A. (Eds), Handbook for Diversity in Organizations, Oxford University Press, Oxford.

Bezrukova, K., Jehn, K.A. and Spell, C.S. (2012), "Reviewing diversity training: where we have been and where we should go", The Academy of Management Learning and Education, Vol. 11 No. 2, pp. 207-227.

Casey, A.J. (1997), "Collective memory in organizations", Advances in Strategic Management, Vol. 14, pp. 111-146.

Casey, A.J. and Olivera, F. (2011), "Reflections on organizational memory and forgetting”, Journal of Management Inquiry, Vol. 20 No. 3, pp. 305-310.

Cavaghan, R. (2013), "Gender mainstreaming in the DGR as a knowledge process: epistemic barriers to eradicating gender bias", Critical Policy Studies, Vol. 7 No. 4, pp. 407-421.

Cockburn, C. (1989), "Equal opportunities: the short and long agenda", Industrial Relations Journal, Vol. 20 No. 3, pp. 213-225.

Cross, R. and Baird, L. (2000), "Technology is not enough: improving performance by building organizational memory", Sloan Management Review, Vol. 41 No. 3, p. 69.

Contu, A. and Willmott, H. (2003), "Re-embedding situatedness: the importance of power relations in learning theory”, Organization Science, Vol. 14 No. 3, pp. 283-296.

Crossan, M.M., Lane, H.W. and White, R.E. (1999), "An organizational learning framework: from intuition to institution", Academy of Management Review, Vol. 24 No. 3, pp. 522-537.

Dass, P. and Parker, B. (1999), "Strategies for managing human resource diversity: from resistance to learning", Academy of Management Perspectives, Vol. 13 No. 2, pp. 68-80.

Davies, A. and Thomas, R. (2008), "Dixon of Dock Green got shot! policing identity work and organizational change", Public Administration, Vol. 86 No. 3, pp. 627-642.

De Vries, J.A. and Van den Brink, M. (2016), "Transformative gender interventions: linking theory and practice using the 'Bifocal Approach", Equality, Diversity and Inclusion: International Journal, Vol. 35 Nos 7/8, pp. 429-448. 
Dobbin, F. and Kalev, A. (2016), "Why diversity programs fail and what works better", Harvard Business Review, Vol. 94 Nos 7-8, pp. 52-60.

Eisenhardt, K.M. and Graebner, M.E. (2007), "Theory building from cases: opportunities and challenges", Academy of Management Journal, Vol. 50 No. 1, p. 25.

Ely, R.J. and Meyerson, D.E. (2000), "Theories of gender in organizations: a new approach to organizational analysis and change", Research in Organizational Behavior, Vol. 22, pp. 103-152.

Eriksson-Zetterquist, U. and Styhre, A. (2008), "Overcoming the glass barriers: reflection and action in the 'women to the top' programme”, Gender, Work and Organization, Vol. 15 No. 2, pp. 133-160.

Evans, C. (2014), "Diversity management and organizational change: what can institutional theory contribute to our understanding of the lack of radical change?", Equality, Diversity and Inclusion: International Journal, Vol. 33 No. 6, pp. 482-493.

Fiedler, M. and Welpe, I. (2010), "How do organizations remember? The influence of organizational structure on organizational memory”, Organization Studies, Vol. 31 No. 4, pp. 381-407.

Foldy, E.G. and Creed, W. (1999), "Action learning, fragmentation, and the interaction of single-, double-, and triple-loop change", The Journal of Applied Behavioral Science, Vol. 35 No. 2, p. 207.

Foster, C. and Harris, L. (2005), 'Easy to say, difficult to do: diversity management in retail', Human Resource Management Journal, Vol. 15 No. 3, pp. 4-17.

Fujimoto, Y. and Härtel, C.E.J. (2017), "Organizational diversity learning framework: going beyond diversity training programs", Personnel Review, Vol. 46 No. 6, pp. 1120-1141.

Georges, L., Romme, A. and Van Witteloostuijn, A. (1999), "Circular organizing and triple loop learning”, Journal of Organizational Change Management, Vol. 12 No. 5, pp. 439-454.

Gherardi, S. (2006), Organizational Knowledge: The Texture of Workplace Learning, Blackwell, Oxford.

Gherardi, S. (2009), "Knowing and learning in practice-based studies: an introduction", The Learning Organization, Vol. 16 No. 5, pp. 352-359.

Henderson, G.M. (2002), "Transformative learning as a condition for transformational change in organizations", Human Resource Development Review, Vol. 1 No. 2, pp. 186-214.

Hernes, T. (2008), "Bruno Latour: relativizing the social, and the becoming of networks", Understanding Organization as Process: Theory for a Tangled World, Routledge, London, New York, pp. 59-77.

Janssens, M. and Steyaert, C. (2019), "A practice-based theory of diversity: respecifying (in) equality in organizations", Academy of Management Review, Vol. 44 No. 3, pp. 518-537.

Kirton, G., Greene, A.M. and Dean, D. (2007), "British diversity professionals as change agentsradicals, tempered radicals or liberal reformers?", The International Journal of Human Resource Management, Vol. 18 No. 11, pp. 1979-1994.

Klarsfeld, A., Knappert, L., Kornau, A., Ngunjiri, F.W. and Sieben, B. (2019), "Diversity in underresearched countries: new empirical fields challenging old theories?", Equality, Diversity and Inclusion: International Journal, Vol. 38 No. 7, pp. 694-704.

Lansu, M.E.M. (2019), Keep talking! Exploring a Participatory Gender Equality Intervention in Science, Doctoral dissertation, Radboud University Nijmegen.

Lawrence, E. (2000), "Equal opportunity officers and managing equality changes", in Personnel Review, Vol. 3, pp. 381-401.

Lansu, M.E.M., Bleijenbergh, I.L. and Benschop, Y. (2019), "Seeing the system. systemic gender knowledge to support transformational change towards gender equality in science", Forthcoming in Gender Work and Organization.

Lave, J. and Wenger, E. (1991), Situated Learning: Legitimate Peripheral Participation, Cambridge University Press. Lawrence, Cambridge.
Organizational learning, memory and forgetting 
EDI 39,4

Leenders, J., Bleijenbergh, I. and Van den Brink, M. (2019), "Myriad potential for mentoring: understanding the process of transformational change through a gender equality intervention", Gender, Work and Organization.

Lorbiecki, A. (2001), "Changing views on diversity management the rise of the learning perspective and the need to recognize social and political contradictions", Management Learning, Vol. 32 No. 3, pp. 345-361.

Meier, P. (2006), "Implementing gender equality: gender mainstreaming or the gap between theory and practice", in Women's Citizenship and Political Rights, Palgrave Macmillan, London, pp. 179-198.

Van Maanen, J., Sørensen, J.B. and Mitchell, T.R. (2007), "Introduction to special topic forum the interplay between theory and method", The Academy of Management Review Archive, Vol. 32 No. 4, pp. 1145-1154.

Meyerson, D.E. and Scully, M.A. (1995), "Crossroads tempered radicalism and the politics of ambivalence and change", Organization Science, Vol. 6 No. 5, pp. 585-600.

Moss-Racusin, C.A., van der Toorn, J., Dovidio, J.F., Brescoll, V.L., Graham, M.J. and Handelsman, J. (2014), "Scientific diversity interventions", Science, Vol. 343 No. 6171, pp. 615-616.

Nicolini, D., Gherardi, S. and Yanow, D. (2003), Introduction in Knowing in Organizations, M. E. Sharpe, Armonk, NY.

Orlikowski, W.J. (1996), "Improvising organizational transformation over time: a situated change perspective", Information systems research, Vol. 7 No. 1, pp. 63-92.

Ortlieb, R. and Sieben, B. (2012), "How to safeguard critical resources of professional and managerial staff: exploration of a taxonomy of resource retention strategies", The international journal of human resource management, Vol. 23 No. 8, pp. 1688-1704.

Parsons, E. and Priola, V. (2013), "Agents for change and changed agents: the micro-politics of change and feminism in the academy", Gender, Work and Organization, Vol. 20 No. 5, pp. 580-598.

Pettigrew, A.M. (1990), "Longitudinal field research on change: theory and practice", Organization Science, pp. 267-292.

Prasad, P. and Mills, A.J. (1997), "From showcase to shadow: understanding the dilemmas of managing workplace diversity", in Prasad, P., Mills, A.J., Elmes, M. and Prasad, A. (Eds), Managing the Organizational Melting Pot: Dilemmas of Workplace Diversity, Sage Publications, pp. 3-27.

Romani, L., Holck, L. and Risberg, A. (2019), "Benevolent discrimination: Explaining how human resources professionals can be blind to the harm of diversity initiatives", Organization, Vol. 26 No. 3, pp. 371-390.

Romme, A.G.L. and Van Witteloostuijn, A. (1999), "Circular organizing and triple loop learning", Journal of Organizational Change Management, Vol. 12 No. 5, pp. 439-454.

Rowlinson, M., Casey, A.J. and Hansen, P.H. (2014), "Narratives and memory in organizations", Organization, Vol. 21 No. 4, pp. 441-446.

Schwandt, D.R. (1997), "Integrating strategy and organizational learning: a theory of action perspective", Advances in Strategic Management, Vol. 14, pp. 337-360.

Silverman, D. (2006), Interpreting Qualitative Data: Methods for Analyzing Talk, Text, and Interaction, Sage Publications, London.

Smith, D.G. and Parker, S. (2005), "Organizational learning: a tool for diversity and institutional effectiveness", New Directions for Higher Education, Vol. 2005 No. 131, pp. 113-125.

Tienari, J., Quack, S. and Theobald, H. (2002), "Organizational reforms, ideal workers' and gender orders: a cross-societal comparison”, Organization Studies, Vol. 23 No. 2, pp. 249-279.

Van der Bent, J., Paauwe, J. and Williams, R. (1999), "Organizational learning: an exploration of organizational memory and its role in organizational change processes", Journal of Organizational Change Management, Vol. 12 No. 5, pp. 377-404. 
Tatli, A. and zbilgin, M.F. (2009), "Understanding diversity managers role in organizational change: towards a conceptual framework", Canadian Journal of Administrative Sciences/Revue Canadienne des Sciences de l'Administration, Vol. 26 No. 3, pp. 244-258.

Van den Brink, M. (2015), "The politics of knowledge: the responses to feminist research from academic leaders", Equality, Diversity and Inclusion: An International Journal, Vol. 34 No. 6, pp. 483-495.

van den Brink, M. (2018), "De zevenkoppige draak van ongelijkheid", Tijdschrift voor Genderstudies, Vol. 21 No. 2, pp. 113-129.

Organizational learning, memory and forgetting

Walsh, J.P. and Ungson, G.R. (1991), "Organizational memory”, Academy of Management Review, Vol. 16 No. 1, pp. 57-91.

Weick, K.E. and Quinn, R.E. (1999), "Organizational change and development”, Annual Review of Psychology, Vol. 50 No. 1, pp. 361-386.

Welp, M. (2002), "Vanilla voices: researching White men's diversity learning journeys", American Behavioral Scientist, Vol. 45 No. 8, pp. 1288-1296.

Yanow, D. (2000), "Seeing organizational learning: a cultural view", Organization, Vol. 7 No. 2, p. 247.

Zanoni, P., Janssens, M., Benschop, Y. and Nkomo, S. (2010), "Guest editorial: unpacking diversity, grasping inequality: rethinking difference through critical perspectives”, Organization, Vol. 17 No. 1, pp. 9-29.

\section{Corresponding author}

Marieke van den Brink can be contacted at: m.vandenbrink@ru.nl

For instructions on how to order reprints of this article, please visit our website:

www.emeraldgrouppublishing.com/licensing/reprints.htm

Or contact us for further details: permissions@emeraldinsight.com 